\title{
Cross-sectional associations of albuminuria among Aboriginal and Torres Strait Islander adults: the eGFR Study
}

JT Hughes ${ }^{1,2}$, LJ Maple-Brown ${ }^{1,2}$, M Thomas ${ }^{3}$, PD Lawton ${ }^{1}$, A Sinha ${ }^{4}$, A Cass $^{1}$, F Barzi $^{1}$, GRD Jones ${ }^{5}$, G Jerums ${ }^{6,7}$, RJ Maclsaac ${ }^{6,8}$, K O'Dea $^{9}$, WE Hoy ${ }^{10}$

\section{Affiliations}

1 Menzies School of Health Research, Charles Darwin University, Darwin, Northern Territory, Australia

2 Department of Medicine, Royal Darwin Hospital, Darwin, Northern Territory, Australia

3 Royal Perth Hospital, Perth, Australia,

4 Cairns Base Hospital and Diabetes Centre, Cairns, Australia

5 SydPath, St Vincent's Hospital, Sydney, Australia

$6 \quad$ University of Melbourne, Melbourne

7 Austin Health, Melbourne, Australia

8 Department of Endocrinology and Diabetes, St Vincent's Hospital, Melbourne

9 Centre for Population Health Research, University of South Australia

10 Centre for Chronic Disease, The University of Queensland, Australia

Running Title: Albuminuria in Indigenous Australians: the eGFR Study

Corresponding author: Jaquelyne T Hughes, BMed FRACP PhD Menzies School of Health Research

Charles Darwin University

Casuarina

NT 0810

AUSTRALIA

Telephone: $+61(0) 889228196$

This is the author manuscript accepted for publication and has undergone full peer review but has not been through the copyediting, typesetting, pagination and proofreading process, which may lead to differences between this version and the Version of Record. Please cite this article as doi: $10.1111 /$ nep.12956

This article is protected by copyright. All rights reserved. 
FAX:

Email:
+61(0)8 89275187

Jaqui.hughes@menzies.edu.au

This article is protected by copyright. All rights reserved. 


\begin{abstract}
Objective: To describe the detailed associations of albuminuria among a contemporary cohort of Aboriginal and Torres Strait Islander people to inform strategies for chronic kidney disease prevention and management.

Methods: A cross-sectional analysis of Indigenous participants of the eGFR Study. Measures: Clinical, biochemical and anthropometric measures were collected (including body-circumferences, blood pressure (BP); triglycerides, HbA1c, liver function tests, creatinine; urine- microscopic-haem, albumin: creatinine ratio (ACR), prescriptions- angiotensin converting enzyme inhibitor or angiotensin receptor II antagonist (ACEl/ARB). Albuminuria and diabetes were defined by an ACR $>3.0$ $\mathrm{mg} / \mathrm{mmol}$, and $\mathrm{HbA} 1 \mathrm{c} \geq 48 \mathrm{mmol} / \mathrm{mol}$ or prior history respectively. Waist: hip ratio (WHR), and estimated glomerular filtration rate (eGFR) were calculated. ACR was non-normally distributed; a logarithmic transformation was applied (in base 2), with each unit increase in log2-albuminuria representing a doubling of ACR.
\end{abstract}

Results: 591 participants were assessed (71\% Aboriginal, 61.6\% female, mean age 45.1 years, BMI $30.2 \mathrm{~kg} / \mathrm{m}^{2}$, WHR 0.94, eGFR $99.2 \mathrm{ml} / \mathrm{min} / 1.73 \mathrm{~m}^{2}$ ). The overall prevalence of albuminuria, diabetes, microscopic-haem and ACEI/ARB use was $41.5 \%, 41.5 \%, 17.8 \%$ and $34.7 \%$ respectively; $69.3 \%$ of adults with albuminuria and diabetes received an ACEI/ARB. Using multivariable linear regression modelling, the potentially modifiable factors independently associated with log2-albuminuria were microscopic-haem, diabetes, WHR, systolic BP, alkaline phosphatase (all positive) and eGFR (inverse).

Conclusion: Albuminuria is associated with diabetes, central obesity and haematuria. High ACEI/ARB prescribing for adults with diabetes and albuminuria was observed. Further understanding of the links between fat deposition, haematuria and albuminuria is required. 


\section{Introduction}

Albuminuria is an indicator of microvascular injury ${ }^{1}$, the metabolic syndrome, diabetic and non-diabetic chronic kidney disease (CKD) and excess cardiovascular disease mortality $^{2-4}$. Guidelines have recently recommended CKD screening and staging using both albuminuria and estimated glomerular filtration rate (eGFR) ${ }^{2}$. Local and national clinical management guidelines for CKD also recommend renoprotective medication use e. $^{5}$.

Albuminuria without impaired $\mathrm{GFR}^{7}$, or which precedes diabetes is a common CKD presentation in Aboriginal and Torres Strait Islander (TSI) people of northern Australia. In this population, albuminuria has been linked with overweight, dialysis dependent end stage kidney disease (ESKD) and mortality ${ }^{8,9}$. Understanding the associations of albuminuria among Aboriginal and Torres Strait Islander people, such as the consistency of clinical prescribing practices for adults with CKD, may highlight health system and broader health promotion measures for ESKD prevention. Our aim was to describe the clinical, anthropometric and biochemical associations of albuminuria among volunteering Aboriginal and Torres Strait Islander adults within different levels of kidney function living across large regions of northern and Central Australia.

\section{Methods}

\section{Participants}

The life expectancy gap attributed to adult chronic diseases has contributed to a younger median age of Indigenous Australians than other Australians (21 v 37 years $)^{10}$. As such, annual health assessments are recommended for Indigenous Australian adults (from the age of fifteen) ${ }^{11}$. Reflecting the different age structures and risks associated with chronic disease, participants in the eGFR Study were selfidentifying Aboriginal and Torres Strait Islander people (Indigenous Australians) aged at least 16 years $^{12}$. With the exception of adults undertaking dialysis, who had rapidly changing kidney function or were pregnant or breastfeeding, all adults 
expressing interest to participate were able to be stratified for inclusion, including those with diabetes or existing kidney disease. Recruitment areas focussed on regions with a high incidence of $\mathrm{ESKD}^{13}$, including more than 20 sites in the Northern Territory, Central Australia, Thursday Island and Far North Queensland, and the Kimberley and Goldfield regions of Western Australia. Although Aboriginal and Torres Strait Islander peoples are both recognised as Indigenous peoples of Australia, there are several unique features including population origins (Micronesia $\checkmark$ Melanesia origins), cultural practises ${ }^{14}$ and patterns of dyslipidaemia ${ }^{15}$. Torres Strait Islander peoples are also a minority group within the Indigenous Australian population $^{16}$, however it was not the goal of the eGFR Study to recruit equal numbers of TSI and Aboriginal participants. Participants provided informed consent. Ethics approval was provided by the Northern Territory Department of Health and Families and Menzies School of Health Research Human Research Ethics Committee, including the Indigenous ethics subcommittee, which has the power of veto over studies involving Indigenous Australian peoples; Cairns and Hinterland Health Services District Human Research Ethics Committee; Central Australian Human Research Ethics Committee; Western Australian Aboriginal Health Information and Ethics Committee; Royal Perth Hospital Ethics Committee.

\section{Measures}

Diabetes was defined by $\mathrm{HbA} 1 \mathrm{c} \geq 48 \mathrm{mmol} / \mathrm{mol}^{17}$ or physician diagnosis or by current use of anti-diabetic medications. Hypertension was defined by physician diagnosis, current use of anti-hypertensive medications or $\mathrm{BP} \geq 140 / 90 \mathrm{mmHg}^{18}$. Blood pressure was described as the mean of three resting blood pressure measurements (taken at least 3 minutes apart) after the participant had been seated quietly for at least 5 minutes using an automated sphygmomanometer as previously described ${ }^{12}$. Current smoking was self-reported. Smoking duration in years was calculated in current smokers. Alcohol excess was recorded if participants recorded no alcohol freedays $^{19}$ or $>20$ units consumed per week. Remoteness index of usual residence was calculated by Accessibility Remoteness Index of Australia with scores $>10.53$ 
indicating residence in a community/ town in very remote Australia ${ }^{20}$. Urine dipstick was used as a screening test to evaluate for the presence of chronic kidney disease $^{21}$. Urine samples were sent for urine culture if urine dipstick was positive for either of nitrites, leucocytes or haem. We describe microscopic-haem as the presence of at least trace haem on urine dipstick, in the absence of bacteriuria defined by the presence of a single bacterial colony count of $\geq 10^{5} / \mathrm{ml}$. In this analysis, bacteriuria is not urinary tract infection. Medication prescriptions for aspirin, HMG-CoA enzyme reductase inhibitors (statins), non-steroidal antiinflammatory drugs (NSAID's), antihypertensive medications including angiotensin converting enzyme inhibitors (ACEI) and angiotensin II receptor antagonists (ARB) were confirmed by the medical record. ACEI/ARB described the prescription with either an ACEI or ARB. Measurements of resting blood pressure, height, weight, waist and hip circumferences and bioimpedance were collected; waist to hip ratio (WHR), body mass index (BMI) and fat-free mass percent (FFM\%) ${ }^{22}$ were calculated. An optimal FFM\% range for healthy middle-aged adults (40-59 years) with BMI $18-25 \mathrm{~kg} / \mathrm{m}^{2}$ in males $(79-89 \%)$ and females $(65-76 \%)$ has been previously described $^{23}$.

Laboratories local to each recruitment site measured non-fasting serum high density lipoprotein (HDL)-cholesterol, glycated haemoglobin (HbA1c), liver function tests and urine albumin to creatinine ratio $(A C R)$. Detailed methods at each laboratory for these measures have been previously described ${ }^{12}$, and each pathology laboratory was accredited by NATA (National Association of Testing Authorities, Australia). Albuminuria was defined as an $A C R>3.0 \mathrm{mg} / \mathrm{mmol}^{2}$. Serum creatinine was measured centrally using an IDMS standardised enzymatic assay ${ }^{24}$, and estimated GFR (eGFR) was calculated by the CKD-EPI formulae without use of the correction for African Americans ${ }^{24}$.

Six hundred and fifty three Indigenous Australian participants were assessed the baseline eGFR Study. This analysis describes adult participants defined as at least 
18 years, since creatinine-derived variables (eGFR) are not validated in populations younger than 18 years. Thus this analysis describes 591 participants accounting for the following exclusions: age $<18$ years $(n=10)$; missing data for urine ACR $(n=46)$; presence of bacteriuria confirmed by urine culture $(n=6)$.

\section{Statistical Analyses}

Descriptive characteristics of participants were reported by Indigenous status (Aboriginal or TSI) and, within each indigenous group, separately for those without and with albuminuria. Categorical variables were described with a percentage and continuous variables, when normally distributed, with mean and standard deviation. Continuous variables with a right skewed distribution were log transformed when possible, otherwise were described with median and interquartile range. $P$ values were derived to test differences in distribution of participants' characteristics between those with and without albuminuria using Chi-squared test for categorical factors and Students t-test for normally distributed continuous factors. The Wilcoxon rank-sum test was used to compare medians in not normally distributed variables.

The outcome of ACR displayed a highly right skewed distribution, thus a logarithmic transformation in base 2 ( $\log 2$-albuminuria) was carried out to normalise the distribution. Therefore each unit rise in log2-albuminuria represents a doubling in ACR.

As the cohort had a higher proportion of females, and aging is associated with chronic disease and adiposity, we used linear regression models, adjusted for age and gender in each indigenous group to examine the effect each variable had on log2-albuminuria, and identify which variables had different coefficient loadings between indigenous groups. A multivariable linear regression analysis was then used to examine the associations between participants' characteristics and the outcome, log2-albuminuria. The initial model was built with gender, ethnicity and age, and all other predictor variables identified on linear modelling with $p<0.10$. 
Using a stepwise backwards process, the final significant model was obtained by removing one variable at a time if its main effect in the model was $p>0.05$, until all remaining variables were significantly associated with the outcome $(p<0.05)$. We assessed and did not observe an interaction between indigenous ethnicity and the other covariates. Collinearity between predictor variables was assessed using the variance of inflation factor, a maximum value of 10 being deemed acceptable. To enhance the clinical interpretation, we subsequently converted the equation from log2-albuminuria to $\mathrm{ACR}$ as the outcome variable, in order to demonstrate the contribution (as percent additive contribution) of each independent variable with estimated ACR (in $\mathrm{mg} / \mathrm{mmol}$ ). Statistical analyses were performed using Stata v14 (Stata Corporation, College Station, TX).

\section{Results}

Albuminuria, diabetes, hypertension and overweight were key findings observed among the 591 participants (Table 1). The median (IQR) ACR in Aboriginal and TSI participants was $2.5(0.7,30.4)$ and $1.1(0.6,4.6) \mathrm{mg} / \mathrm{mmol}$ respectively $(p<0.001)$. A higher proportion of older participants (>60 years) and Aboriginal participants had albuminuria and low eGFR (<60 ml/min/1.73 ${ }^{2}$ ) (Table 2). Microscopic-haem was observed in $17.8 \%$ of participants overall, including in adults with and without albuminuria $(23.9 \%, 13.5 \%, \mathrm{p}=0.002)$. A wide range in $\mathrm{FFM} \%$ was observed in participants (49-94\%), though FFM\% overall was lower in Aboriginal than TSI participants (Aboriginal, mean (SD): 64.9 (9.7) \% v TSI: mean (SD): 66.9 (9.4) \%, $p=0.03$ ). As expected, FFM\% was higher in males than females (74 (8.3) v 60.3 (6.0) \%, p<0.001). ACEI/ARB's were the most commonly prescribed class of antihypertensive medications (Table 3). The highest frequency of medication prescription for ACEI/ARB, statins and aspirin was observed in adults with albuminuria who also had diabetes (Figure 1).

Characteristics of participants with albuminuria (ACR $>3.0 \mathrm{mg} / \mathrm{mmol}$ ) included older age, diabetes, hypertension, abdominal obesity, use of ACEI/ARB and statins, higher 
values each of systolic and diastolic blood pressure, $\mathrm{HbA1c}$ and alkaline phosphatase, and lower eGFR (Table 3). Albuminuria was also associated with higher WHR (without a comparably higher value in BMI or weight) in Aboriginal male and female participants. In contrast, TSI males with albuminuria had a larger body size marked by higher adiposity (indicated by higher weight, higher BMI and lower FFM\%) in addition to higher WHR than TSI males with normoalbuminuria. By comparison (and unlike Aboriginal females), albuminuria in TSI females was not significantly associated with WHR (Table 3).

Bivariate analysis showed significant associations between log2-albuminuria and WHR ( $r=0.34)$ and serum GGT $(r=0.19)$ respectively. GGT was also positively associated with WHR ( $r=0.26)$, ALP ( $r=0.40)$ and diabetes (35 $29 \mathrm{U} / \mathrm{L}, \mathrm{p}=0.017)$. Bilirubin was inversely associated with ALP ( $r=-0.19)$. High serum GGT (>50 U/L) was observed in $31 \%$ of participants, though reporting of excess alcohol consumption was low in participants ( $n=49,8.3 \%)$.

\section{Linear Regression modelling adjusted for age and gender}

Log2-albuminuria when adjusted for age and gender, was independently associated with the following variables in all participants ( $p \leq 0.001)$ : microscopic-haem, diabetes, WHR, total cholesterol, aspirin use, statin use, ACEI/ARB use, hypertension, systolic $\mathrm{BP}$, diastolic BP, HbA1c, HDL-cholesterol, alkaline phosphatase, GGT, triglycerides, (all positive) and eGFR (inverse) and bilirubin (inverse); and at the level of $p<0.10$ as follows: waist $(p=0.06)$ and total protein $(p=0.07)$. Differences in the coefficient loading between Indigenous groups (beta coefficient, Aboriginal, TSI) were noted respectively for: diabetes $(2.54,1.46)$, microscopic-haem $(2.0,1.0)$, WHR $(8.12$, $7.40)$, aspirin use $(1.87,0.92)$ and total cholesterol $(-0.37,-0.13)$.

Log2-albuminuria when adjusted for age and gender, was not linearly associated in the aggregate group with: height $(p=0.10)$, alanine transferase $(p=0.14)$, remoteness index $(p=0.16), H D L$ : total cholesterol ratio $(p=0.21), F F M \%(p=0.32)$, current 
smoking $(p=0.56)$, NSAID use $(p=0.72)$, weight $(p=0.74)$ and body mass index $(p=0.94)$.

In the multivariable linear regression model in all participants (Table 4), 56\% of the variance in log2-albuminuria was explained by Aboriginal ethnicity, female sex, WHR, systolic blood pressure, diabetes, ACEI/ARB use, ALP and microscopic-haem (all were positive associations), and lower eGFR. ACEI/ARB use explained $2.2 \%$ of the $56 \%$ variance in log2-albuminuria among all participants. Table 5 shows the contribution of each independent variable with estimated ACR (as an untransformed variable in $\mathrm{mg} / \mathrm{mmol}$ ). For example, using the simulated patients, with all measures being equal, diabetes explained an additive $186 \%$ higher estimated ACR than the value observed in participants without diabetes (patient $6 \vee 5$ : ACR $13 \mathrm{mg} / \mathrm{mmol} \vee 5$ $\mathrm{mg} / \mathrm{mmol})$.

\section{Discussion}

We examined the cross-sectional associations of albuminuria among 591 Indigenous Australian adults of the eGFR Study, who were recruited across multiple northern and Central Australian sites and had fulfilled the pre-defined recruitment criteria of good health, increased cardio-metabolic risk or CKD. Of the ten factors identified in the multivariable linear regression model, the categorical factors strongly associated with estimated ACR as potential targets of disease prevention and mitigation were diabetes and microscopic-haem. Furthermore systolic blood pressure, lower eGFR and higher WHR were the continuous variables which were most strongly associated with estimated ACR. Other key findings of this analysis included the strong association of albuminuria with features of the metabolic syndrome among participants; the co-existence of microscopic-haem in a population with a high frequency of diabetes; and the high prescription rates of renoprotective agents among adults with co-existing cardio-metabolic risks including diabetes, hypertension and albuminuria. 


\section{Albuminuria, ALP, GGT and central and total adiposity}

Alkaline phosphatase, GGT, uric acid and albuminuria are all biochemical markers associated with the metabolic syndrome ${ }^{25-27}$. GGT and ALP are both correlated with abdominal adiposity ${ }^{27}$ and GGT can indirectly predict ultrasound-proven hepatic steatosis $^{28}$, a condition within the metabolic syndrome spectrum. In one remote Aboriginal community, it was previously reported that albuminuria was positively associated with several cardio-metabolic disease risk markers: blood pressure, uric acid, diabetes, CRP and serum GGT $(p=0.05)^{29}$. Additionally, comparable decreases in GGT concentrations over time were associated with lower waist circumference among Indigenous adults of north Queensland ${ }^{30}$. We suggest hepatic steatosis is likely among Aboriginal participants when overweight, given the positive association of GGT and ALP with WHR and log2-albuminuria in our study. This may result from a low threshold for hepatic lipid storage resulting in preferential central adiposity that accompanies elevated fasting insulin concentrations. It is proposed that these elevated insulin concentrations are to historically mitigate periods of recurrent relative low food intake ${ }^{31}$. A low threshold for hepatic lipid storage may also be consequent to limited peripheral adipose storage depots, due to a lower absolute lean mass.

Log2-albuminuria was strongly associated with WHR in the multivariate regression model, which is an observation consistent among Aboriginal people across northern and Western Australia ${ }^{32}$. Among Aboriginal participants, this central fat distribution (at comparably lower BMI than TSI participants) is likely to be a progression of the physique described by Piers et al. who reported a higher WHR, and percent fat adjusted for BMI in healthy Aboriginal young adults relative to Caucasian participants ${ }^{33}$.

In this analysis, overweight was a common feature of participants, indicated by high WHR, BMI and low FFM\%. These low FFM\% values were comparable to previous reported values in Aboriginal adults of similar age and $\mathrm{BMI}^{34,35}$. Consistent with 
other studies, we report a higher FFM\% in TSI than Aboriginal participants ${ }^{36}$. We note adults with higher (than lower) FFM\% have an enhanced capacity for insulin secretion $^{37}$. This might suggest TSI groups have an optimised capacity for insulin clearance across a larger weight-range due to a higher proportion of lean mass than Aboriginal people ${ }^{36}$, and is consistent with the lack of association of log2-albuminuria with $\mathrm{FFM} \%$ in participants in this analysis.

Central obesity (than total obesity) was previously reported to be more strongly associated with cardio-metabolic risk across multi-ethnic populations ${ }^{38}$. Likewise, we show that albuminuria is associated with WHR and ALP (and not with FFM\%). WHR in combination with ALP may have better defined the physical attributes related to the metabolic syndrome of each indigenous group. The Aboriginal ethnicity covariate may have further explained the difference in body fat distribution between groups.

\section{Microscopic haem}

Albuminuria was observed in participants with and without diabetes and with and without microscopic-haem as detected by urine dipstick. This association is consistent with the leading clinical diagnoses of Indigenous Australians with ESKD ${ }^{39}$, and also consistent with the mixed and overlapping renal pathologies in biopsy series of remote living Aboriginal people with diabetes ${ }^{40}$. One remote Aboriginal community with a high risk of ESKD had documented haematuria amongst $25 \%$ of adults $^{41}$. A greater understanding of the pathogenic impact of microscopic-haem in diabetic and non-diabetic CKD in both Indigenous groups is needed.

\section{Renin-Angiotensin system blockade}

As in other populations, angiotensin converting enzyme inhibitors have demonstrated renoprotective effects in Aboriginal Australians ${ }^{42,43}$, and are the cornerstone of medical treatment guidelines for adults with $\mathrm{CKD}^{5}$. The use of an ACEI/ARB is in large part a treatment decision for cardio-metabolic risk modification 
related to albuminuria, diabetes, and hypertension. The extent to its use may vary according to the health service provider awareness and vigour. In this analysis, there was high alignment with guidelines for ACEI/ARB prescribing for adults with diabetes, which were often co-prescribed with statins and aspirin. The majority of albuminuric participants without diabetes had micro-albuminuria (ACR 3-30 $\mathrm{mg} / \mathrm{mmol}$ ) and preserved eGFR. In this group ACEI/ARB prescribing practices were again consistent with local and national guidelines, since their use is not recommended for normotensive, non-diabetic adults with micro-albuminuria and preserved eGFR ${ }^{5,6}$. This cross-sectional analysis reports the positive association of ACEI/ARB use with albuminuria. We suggest ACEI/ARB are beneficial agents, and the model identifies they are being used substantially for the treatment of albuminuria or conditions associated with albuminuria (including diabetes and hypertension). The lower frequency of current smokers in adults with albuminuria suggests participants' engagement in health education strategies.

Several key strengths of this study suggest generalisability of our findings. We assessed a large cohort, involving sites across five major Australian regions, and included participants with a wide range of eGFR, and used measures validated in Indigenous Australians (FFM\%, eGFR). We have highlighted the key modifiable factors associated with albuminuria in Indigenous Australians, and the betweengroup differences of albuminuria in this population, which is relevant in informing health intervention strategies. Some limitations are acknowledged; the study was not intended to be population representative, and our findings may be subject to volunteer bias thereby limiting generalisability. We recruited 653 Indigenous participants in the eGFR study, and the 62 participants who were excluded from this analysis (due to missing ACR values, young age or bacteriuria) were younger and had a lower WHR. Furthermore, the final multivariable regression model describes $517 / 591$ participants with complete data for all 10 variables. The serum alkaline phosphatase concentration was higher in participants included in the final model, which may affect the strength of association of the factors with log2-albuminuria. In 
this analysis the description of microscopic-haem was based on urine dipstick rather than the gold standard measure defined as microscopic urinary red blood cells $\geq 3$ 5/HPC on centrifuged urine. Albuminuria and microscopic-haem were measured once, thus misclassification was possible, but minimised by independent medical record review. It was not possible to distinguish microscopic-haem as glomerular or lower urinary tract origin, or explore the association of albuminuria with diet, weight trajectory or other lifestyle factors.

\section{Conclusions}

We report a strong cross-sectional association of log2-albuminuria with abdominal obesity, diabetes and microscopic-haem among Indigenous Australian participants who are relatively younger than other populations with chronic kidney disease. There was also high ACEI/ARB use in adults with diabetes and albuminuria. Although the mechanisms linking albuminuria, abdominal obesity and fatty liver remain to be elucidated, these associations were striking in participants. Further understanding of the links between fat deposition, haematuria and albuminuria is required, in order to strengthen the public health strategies for obesity, diabetes and CKD.

\section{Acknowledgments}

We thank the participants, study staff, community facilitators, and other investigators (L.Ward, R. MacDermott, L.S. Piers, K. Warr, S. Cherian, and W. Majoni) of the eGFR Study; Roche Diagnostics for enzymatic creatinine reagents; and Melbourne Pathology for technical support in enzymatic creatinine analysis. JH was supported by NHMRC Fellowship \#1092576 and Jacquot Research Establishment Award; LMB was supported by NHMRC Fellowship \#1078477; PDL was supported by NHMRC Scholarship \#1038721 and Jacquot Research Establishment Award. FB was supported by NHMRC Program Grant \#631947. The views expressed in this publication are those of the authors and do not reflect the views of the NHMRC. The 
funders had no role in study design, data collection and analysis, decision to publish or preparation of the manuscript.

This article is protected by copyright. All rights reserved. 


\section{References}

1. Deckert T, Kofoed-Enevoldsen A, Nørgaard K, Borch-Johnsen K, FeldtRasmussen $B$, Jensen T. Microalbuminuria: Implications for micro- and macrovascular disease. Diabetes Care 1992; 15(9): 1181-91.

2. Levey AS, de Jong PE, Coresh J, et al. The definition, classification, and prognosis of chronic kidney disease: a KDIGO Controversies Conference report. Kidney Int 2011; 80(1): 17-28.

3. Keith DS, Nichols GA, Gullion CM, Brown JB, Smith DH. Longitudinal Followup and Outcomes Among a Population With Chronic Kidney Disease in a Large Managed Care Organization. Arch Int Med 2004; 164(6): 659-63.

4. Alberti KGMM, Zimmet P, Shaw J. Metabolic syndrome-a new world-wide definition. A Consensus Statement from the International Diabetes Federation. Diab Med 2006; 23(5): 469-80.

5. Johnson DW, Atai E, Chan M, et al. KHA-CARI Guideline: Early chronic kidney disease: Detection, prevention and management. Nephrology 2013; 18(5): 340-50.

6. CARPA. Chronic kidney disease. CARPA Standard Treatment Manual 6th ed. Alice Springs: Centre for Remote Health. ; 2014. p. 282-5.

7. Maple-Brown L, Cunningham J, Hodge A, et al. High rates of albuminuria but not of low eGFR in Urban Indigenous Australians: the DRUID Study. BMC Public Health 2011; 11(1): 346.

8. Lawton PD, Cunningham J, Hadlow N, Zhao Y, Jose MD. Chronic kidney disease in the Top End of the Northern Territory of Australia, 2002-2011: a retrospective cohort study using existing laboratory data. BMC Nephrol 2015; 16 : 168.

9. Hoy WE, Wang Z, vanBuynder P, Baker PRA, McDonald SM, Mathews JD. The natural history of renal disease in Australian Aborigines. Part 2. Albuminuria predicts natural death and renal failure. Kidney Int 2001; 60(1): 249-56.

10. Australian Institute of Health and Welfare 2011. The health and welfare of Australia's Aboriginal and Torres Strait Islander people, an overview 2011. Cat. no. IHW 42. Canberra: AIHW. [Access date: 22 Agust 2016]. Available from: http://www.aihw.gov.au/indigenous-observatory/health-and-welfare/ .

11. Australian Government Department of Health (2013). Medicare Health Assessment for Aboriginal and Torres Strait Islander People- MBS item 715, October 2013. Commonwealth of Australia, Canberra. [Access date 22 August 2016]. Available from: http://www.health.gov.au/internet/main/publishing.nsf/Content/mbsprimarycare_ATSI MBSitem715.

12. Maple-Brown L, Lawton P, Hughes J, et al. Study Protocol-accurate assessment of kidney function in Indigenous Australians: aims and methods of the eGFR study. BMC Public Health 2010; 10: 80. 
13. Cass A, Cunningham J, Wang Z, Hoy W. Regional variation in the incidence of end-stage renal disease in Indigenous Australians. Med J Aust 2001; 175(1): 24 7.

14. Horton D. Australian Institute of Aboriginal and Torres Strait Islander Studies. The Encyclopedia of Aboriginal Australia: Aboriginal and Torres Strait Islander History, Society and Culture In: Horton D, editor. Canberra: Aboriginal Studies Press for the Australian Institute of Aboriginal and Torres Strait Islander Studies; 1994. p. $1089,92$.

15. O'Neal DN, Piers LS, Iser DM, et al. Australian Aboriginal people and Torres Strait Islanders have an atherogenic lipid profile that is characterised by low HDLcholesterol level and small LDL particles. Atherosclerosis 2008; 201(2): 368-77. 16. Australian Bureau of Statistics. (2013). Estimates of Aboriginal and Torres Strait Islander Australians, June 2011 (cat. no. 3238.0.55.001). [Access date: 18 May 2016]. Available from:

http://www.abs.gov.au/AUSSTATS/abs@.nsf/Lookup/3238.0.55.001Main+Features1 June\%202011?OpenDocument

17. Selvin E, Steffes MW, Gregg E, Brancati FL, Coresh J. Performance of A1C for the Classification and Prediction of Diabetes. Diabetes Care 2011; 34(1): 84-9.

18. Lenfant C, Chobanian AV, Jones DW, Roccella EJ. Seventh Report of the Joint National Committee on the Prevention, Detection, Evaluation, and Treatment of High Blood Pressure (JNC 7): Resetting the Hypertension Sails. Circulation 2003; 107(24): 2993-4.

19. National Health and Medical Research Council. NHMRC Australian Guidelines to reduce health risks from drinking alcohol. Commonwealth of Australia: National Health and Medical Research Council; 2009 Jan 1 [Available from: http://www.nhmrc.gov.au/_files_nhmrc/publications/attachments/ds10-alcohol.pdf]. . 20. Australian Bureau of Statistics. Remoteness Structure. June 2014. http://www.abs.gov.au/websitedbs/d3310114.nsf/home/remoteness+structure. 21. Johnson CA, Levey AS, Coresh J, Levin A, Lau J, Eknoyan G. Clinical practice guidelines for chronic kidney disease in adults: Part II. Glomerular filtration rate, proteinuria, and other markers. Am Fam Physician 2004; 70(6): 1091-7.

22. Hughes JT, Maple-Brown LJ, Piers LS, Meerkin J, O'Dea K, Ward LC. Development of a single frequency bioimpedance prediction equation for fat-free mass in an adult Indigenous Australian population. Eur J Clin Nutr 2015; 69: 28-33. 23. Gallagher D, Heymsfield SB, Heo M, Jebb SA, Murgatroyd PR, Sakamoto Y. Healthy percentage body fat ranges: an approach for developing guidelines based on body mass index. Am J Clin Nutr 2000; 72(3): 694-701.

24. Maple-Brown LJ, Hughes JT, Lawton PD, et al. Accurate Assessment of Kidney Function in Indigenous Australians: The Estimated GFR Study. Am J Kidney Dis 2012; 60(4): 680-2.

25. Lee DS, Evans JC, Robins SJ, et al. Gamma Glutamyl Transferase and Metabolic Syndrome, Cardiovascular Disease, and Mortality Risk: The Framingham Heart Study. Arterioscler, Thromb Vasc Biol 2007; 27(1): 127-33. 
26. World Health Organization. Definition, Diagnosis and Classification of Diabetes Mellitus and its Complications; Part 1: Diagnosis and Classification of Diabetes Mellitus. Geneva: Department of Noncommunicable Disease Surveillance, WHO, 1999.

27. Kim MK, Baek KH, Kang MI, et al. Serum alkaline phosphatase, body composition, and risk of metabolic syndrome in middle-aged Korean. Endocr J 2013; 60(3): 321-8.

28. Bedogni G, Bellentani S, Miglioli L, et al. The Fatty Liver Index: a simple and accurate predictor of hepatic steatosis in the general population. BMC Gastroenterol 2006; 6(1): 1-7.

29. Wang Z, Hoy W, Wang Z. The correlates of urinary albumin to creatinine ratio (ACR) in a high risk Australian aboriginal community. BMC Nephrology 2013; 14(176).

30. D'Onise K, McDermott RA, Campbell SK. Benefits of modest weight or waist circumference loss in a remote North Queensland Indigenous population. Aust N Z J Public Health 2013; 37(4): 345-9.

31. O'Dea K, White N, Sinclair A. An investigation of nutrition-related fators in an isolated Aboriginal community in Northern Australia: advantages of a traditionallyoriented life-style. Med J Aust 1988; 148: 177-80.

32. Rowley KG, Iser DM, Best JD, O'Dea K, Leonard D, McDermott R.

Albuminuria in Australian Aboriginal people: prevalence and associations with components of the metabolic syndrome. Diabetologia 2000; 43(11): 1397-403.

33. Piers LS, Rowley KG, Soares MJ, O'Dea K. Relation of adiposity and body fat distribution to body mass index in Australians of Aboriginal and European ancestry. Eur J Clin Nutr 2003; 57(8): 956-63.

34. Rutishauser I, McKay H. Anthropometric status and body composition in Aboriginal women of the Kimberley region. Med J Aust 1986; 144: S8-10.

35. Mendham AE, Coutts AJ, Duffield R. The acute effects of aerobic exercise and modified rugby on inflammation and glucose homeostasis within Indigenous Australians. Eur J Appl Physiol 2012; 112(11): 3787-95.

36. Heitmann BL, Swinburn BA, Carmichael $\mathrm{H}$, et al. Are there ethnic differences in the association between body weight and resistance, measured by bioelectrical impedance? Int J Obes 1997; 21(12): 1085-92.

37. Yki-Jarvinen H, Koivisto VA, Karonen SL. Influence of body composition on insulin clearance. Clin Physiol 1985; 5(1): 45-52.

38. Yusuf S, Hawken S, Ônpuu S, et al. Effect of potentially modifiable risk factors associated with myocardial infarction in 52 countries (the INTERHEART study): case-control study. The Lancet 2004; 364(9438): 937-52.

39. McDonald S. Incidence and treatment of ESRD among indigenous people of Australasia. Clinical Nephrology 2010; 73(S1): S28-S31.

40. Moore L, Lloyd M, Pugsley D, Seymour A. Renal Disease in the Australian Aboriginal population: a pathological study. Nephrology 1996; 2: 315-21. 
41. Hoy WE, Norman RJ, Hayhurst BG, Pugsley DJ. A health profile of adults in a Northern Territory aboriginal community, with an emphasis on preventable morbidities. Aust N Z J Public Health 1997; 21(2): 121-6.

42. Strippoli GFM, Bonifati C, Craig ME, Navaneethan SD, Craig JC. Angiotensin converting enzyme inhibitors and angiotensin II receptor antagonists for preventing the progression of diabetic kidney disease. Cochrane Database of Systematic Reviews 2006; (4).

43. Hoy WE, Wang Z, Baker PRA, Kelly AM. Secondary Prevention of Renal and Cardiovascular Disease: Results of a Renal and Cardiovascular Treatment Program in an Australian Aboriginal Community. J Am Soc Nephrol 2003; 14(Supplement 2): S178-85. 


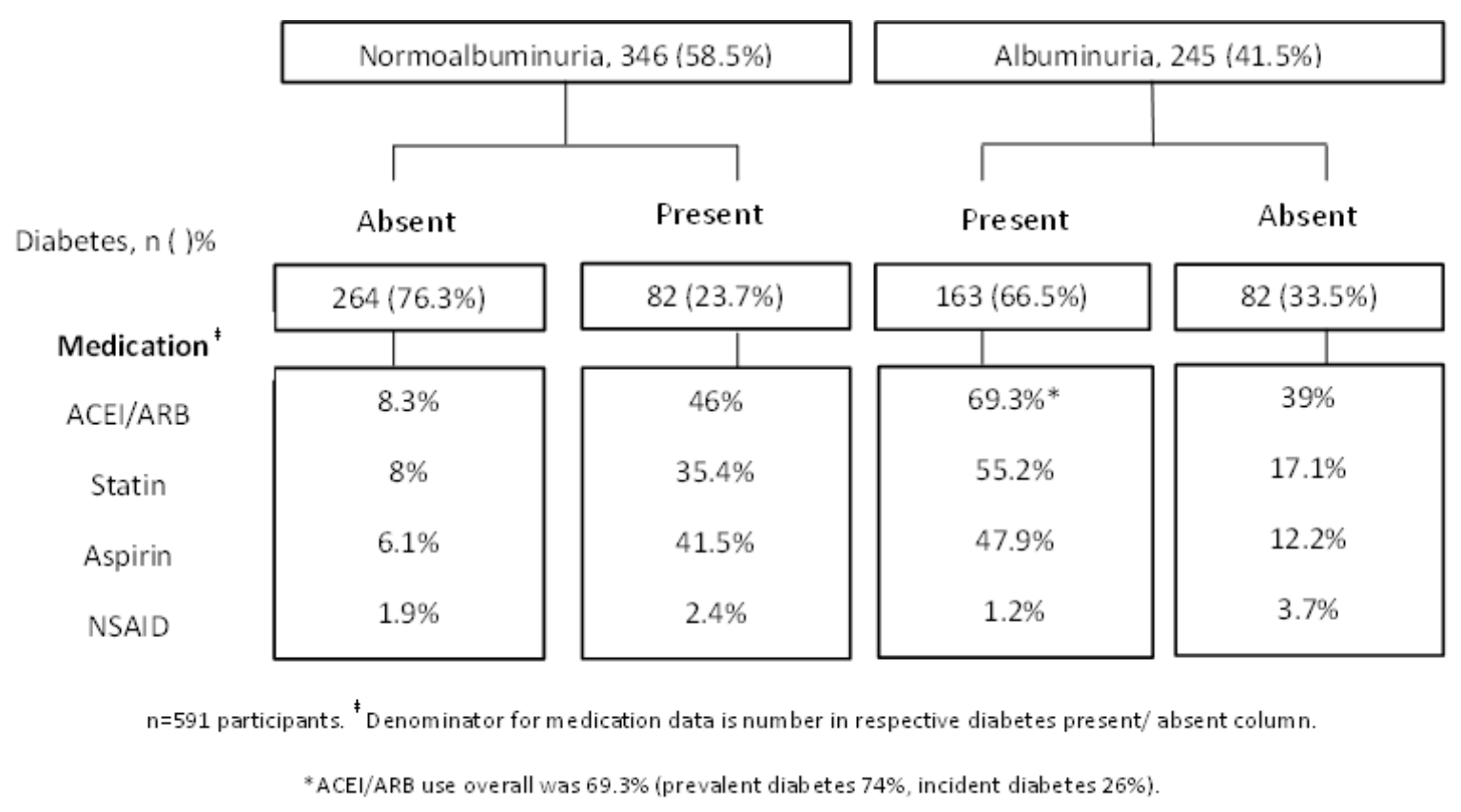

Figure 1: Medication prescription among participants by albuminuria and diabetes

This article is protected by copyright. All rights reserved. 
Table 1: Participant characteristics

$\mathrm{n}(\%)$

Aboriginal Ethnicity

419 (70.9\%)

Female sex

$364(61.6 \%)$

Usual residence: very remote

344 (59.6\%)

Diabetes

$245(41.5 \%)$

Hypertension

255 (43.1\%)

Albuminuria ${ }^{\ddagger}$

245 (41.5\%)

$122(49.8 \%)$

Prevalent Case

$100(40.8 \%)$

Haematuria ${ }^{\#}$

99 (17.8\%)

eGFR<60 ml/min $/ 1.73 \mathrm{~m}^{2 \#}$

103 (17.5\%)

$\mathrm{BMI}>25 \mathrm{~km} / \mathrm{m}^{2}$

$450(76.6 \%)$

Mean (standard deviation)

Age, years

$45.1(14.6)$

$\mathrm{eGFR}^{\mathrm{l}}, \mathrm{ml} / \mathrm{min} / 1.73 \mathrm{~m}^{2 \text { \# }}$

$99.2(79.8-112.3)$

$\mathrm{ACR}^{1}, \mathrm{mg} / \mathrm{mmol}$

1.9 (0.7-17.3)

$\mathrm{HbA} 1 \mathrm{c}, \mathrm{mmol} / \mathrm{mol}$

50 (19.6)

Systolic BP, mmHg

118 (18)

Diastolic BP, $\mathrm{mmHg}$

75 (10)

BMI, $\mathrm{kg} / \mathrm{m}^{2}$

$30.2(7.2)$

FFM \% males

64.4 (11.4)

FFM \% females

48.1 (9.0)

WHR males

0.98 (0.09)

WHR females

$0.92(0.08)$

Data are number (\%) or mean (SD) or ' median (interquartile range). $n=591$. \#Incomplete data as follows: usual residence category (577), haematuria (556), eGFR (589), HbA1c (575), blood pressure (582), BMI (587), FFM\% (524), WHR (560). 'Enable to categorise albuminuria as incident or prevalent in $n=23 / 245$ (9.4\%) participants. Abdominal obesity is defined by WHR $>0.90$ in males and $>0.85$ in females and $/$ or $B M l>30 \mathrm{~kg} / \mathrm{m}^{226}$

This article is protected by copyright. All rights reserved. 
Table 2: The distribution of participants by female gender, albuminuria and low eGFR, and by indigenous ethnicity, age and BMI

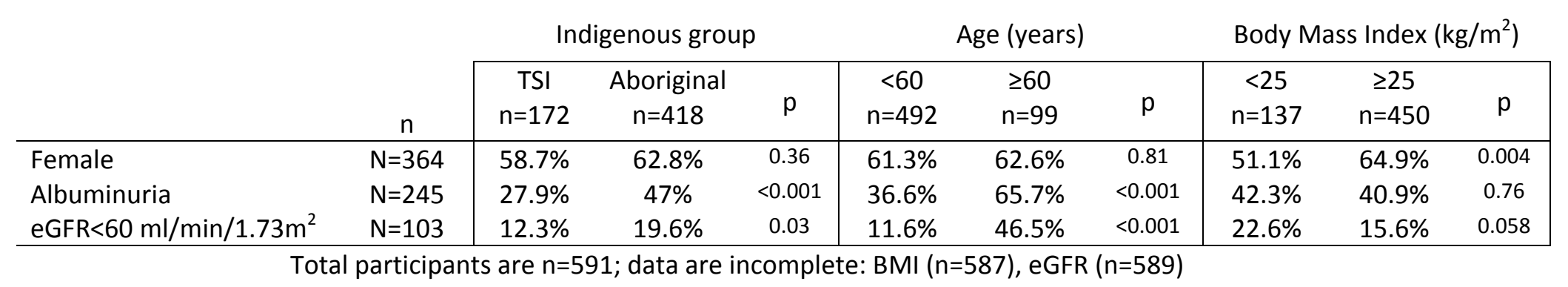

This article is protected by copyright. All rights reserved. 
Table 3: Descriptive characteristics participants without and with albuminuria, by ethnicity and gender

\begin{tabular}{|c|c|c|c|c|c|c|c|c|c|c|c|c|c|}
\hline \multirow{3}{*}{ 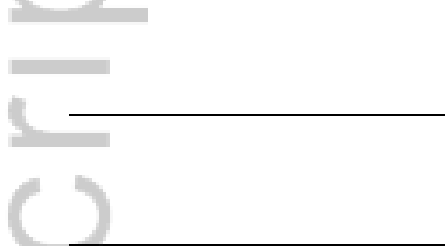 } & & \multicolumn{6}{|c|}{ Aboriginal } & \multicolumn{6}{|c|}{ Torres Strait Islander } \\
\hline & & \multicolumn{2}{|c|}{ Female } & \multicolumn{4}{|c|}{ Males } & \multicolumn{2}{|c|}{ Females } & \multicolumn{4}{|c|}{ Males } \\
\hline & $\mathrm{n}$ & $\begin{array}{c}\text { Normo- } \\
\text { albuminuria } \\
\mathrm{N}=141\end{array}$ & $\begin{array}{l}\text { Albuminuria } \\
\qquad \mathrm{N}=122\end{array}$ & $\begin{array}{c}P \\
\text { value }\end{array}$ & $\begin{array}{c}\text { Normo- } \\
\text { albuminuria } \\
\mathrm{N}=81\end{array}$ & $\begin{array}{l}\text { Albuminuria } \\
\qquad \mathrm{N}=75\end{array}$ & $\begin{array}{c}P \\
\text { value }\end{array}$ & $\begin{array}{c}\begin{array}{c}\text { Normo- } \\
\text { albuminuria } \\
\mathrm{N}=70\end{array} \\
\end{array}$ & $\begin{array}{l}\text { Albuminuria } \\
\qquad \mathrm{N}=31\end{array}$ & $\begin{array}{c}P \\
\text { value }\end{array}$ & $\begin{array}{c}\text { Normo- } \\
\text { albuminuria } \\
\mathrm{N}=54\end{array}$ & $\begin{array}{l}\text { Albuminuria } \\
\qquad \mathrm{N}=17\end{array}$ & $\begin{array}{c}P \\
\text { value }\end{array}$ \\
\hline \multicolumn{14}{|l|}{$n(\%)$} \\
\hline Very remote residence & 577 & $69(50.4)$ & $58(48.7)$ & 0.795 & $45(55.6)$ & $35(48)$ & 0.345 & $60(87.0)$ & $23(74.2)$ & 0.116 & $41(80.4)$ & $13(81.3)$ & 0.940 \\
\hline Diabetes & 591 & $34(24.1)$ & $84(68.9)$ & $<0.001$ & $15(18.5)$ & $49(65.3)$ & $<0.001$ & $20(28.6)$ & $19(61.3)$ & 0.002 & $13(24.1)$ & $11(64.7)$ & 0.002 \\
\hline Hypertension & 585 & $40(28.4)$ & $85(69.7)$ & $<0.001$ & $18(22.2)$ & $50(66.6)$ & $<0.001$ & $19(27.1)$ & $16(51.6)$ & 0.017 & $17(31.5)$ & $10(58.8)$ & 0.043 \\
\hline Current smoking & 580 & $64(46.4)$ & $39(32.8)$ & 0.026 & $42(51.9)$ & $32(43.2)$ & 0.284 & $27(38.6)$ & $7(23.3)$ & 0.140 & $25(48.1)$ & $3(18.8)$ & 0.037 \\
\hline Microscopic-haem & 556 & $24(17.9)$ & $30(26.3)$ & 0.110 & $2(2.8)$ & $15(20.8)$ & 0.001 & $12(18.2)$ & $7(25.9)$ & 0.400 & $6(11.8)$ & $3(17.7)$ & 0.535 \\
\hline Medication Prescription & & & & & & & & & & & & & \\
\hline Any BP medication & 591 & $28(19.5)$ & $75(61.4)$ & $<0.001$ & $14(17.3)$ & $49(65.3)$ & $<0.001$ & $12(17.1)$ & $19(61.3)$ & $<0.001$ & $11(20.4)$ & 9 (52.9) & 0.009 \\
\hline ACEI/ARB & 591 & $26(18.4)$ & $73(59.8)$ & $<0.001$ & $14(17.3)$ & $45(60.0)$ & $<0.001$ & $10(14.3)$ & $18(58.1)$ & $<0.001$ & $10(18.5)$ & 9 (52.9) & 0.005 \\
\hline Statin & 591 & $23(16.3)$ & $49(40.2)$ & $<0.001$ & $7(8.6)$ & $33(44.0)$ & $<0.001$ & $11(15.7)$ & $14(45.2)$ & 0.002 & $9(16.7)$ & $8(47.1)$ & 0.010 \\
\hline Aspirin & 591 & $18(12.8)$ & $36(29.5)$ & 0.001 & $9(11.1)$ & $34(45.3)$ & $<0.001$ & $14(20)$ & $12(38.7)$ & 0.047 & $9(16.7)$ & $6(35.3)$ & 0.101 \\
\hline NSAID & 591 & $2(1.4)$ & $2(1.6)$ & 0.884 & $2(2.5)$ & $1(1.3)$ & 0.606 & $1(1.4)$ & $0(0)$ & 0.504 & $2(3.7)$ & $2(11.8)$ & 0.209 \\
\hline \multicolumn{14}{|c|}{ Mean (Standard deviation) } \\
\hline Age (years) & 591 & $42.0(13.5)$ & $51.0(13.6)$ & $<0.001$ & $37.9(13.3)$ & $50.8(13.9)$ & $<0.001$ & $42.7(13.7)$ & $49.3(14.7)$ & 0.033 & $40.7(15.8)$ & $52.4(10.5)$ & 0.006 \\
\hline Height $(\mathrm{cm})$ & 587 & $163.1(7.2)$ & $161.7(6.1)$ & 0.086 & $172.5(5.3)$ & $172.0(6.7)$ & 0.001 & $161.9(5.8)$ & $161.6(5.0)$ & 0.82 & $173.6(6.4)$ & $173.9(6.0)$ & 0.88 \\
\hline Weight (kg) & 589 & $79.9(19.2)$ & $78.9(19.5)$ & 0.68 & $83.2(20.2)$ & $86.3(21.8)$ & 0.35 & $84.5(19.5)$ & $91.3(21.2)$ & 0.12 & $93.0(24.8)$ & $108.6(18.7)$ & 0.02 \\
\hline $\mathrm{BMI}$ & 587 & $29.9(6.5)$ & $30.2(7.3)$ & 0.78 & $26.9(6.1)$ & $29.0(6.8)$ & 0.046 & $32.2(6.8)$ & $35.0(8.0)$ & 0.073 & $30.8(8.0)$ & $35.8(5.3)$ & 0.02 \\
\hline Waist $(\mathrm{cm})$ & 564 & $99.6(14.7)$ & $102.6(15.9)$ & 0.13 & $96.0(17.8)$ & $104.0(15.5)$ & 0.003 & $100.0(15.6)$ & $104.3(13.8)$ & 0.20 & $100.8(18.5)$ & $117.0(12.2)$ & 0.002 \\
\hline Waist-hip ratio & 560 & $0.91(0.08)$ & $0.95(0.09)$ & 0.001 & $0.95(0.10)$ & $1.03(0.08)$ & $<0.001$ & $0.88(0.07)$ & $0.91(0.09)$ & 0.241 & $0.94(0.08)$ & $1.03(0.05)$ & $<0.001$ \\
\hline Fat free mass (\%) & 524 & $60.1(5.9)$ & $59.5(5.8)$ & 0.38 & 75.1 (7.9) & $72.8(8.7)$ & 0.12 & $61.8(6.5)$ & $61.5(6.2)$ & 0.85 & $75.2(8.9)$ & $70.2(3.7)$ & 0.034 \\
\hline $\mathrm{SBP}(\mathrm{mmHg})$ & 582 & $113(15)$ & $124(20)$ & $<0.001$ & $117(14)$ & $127(21)$ & 0.001 & $109(15)$ & $122(4)$ & 0.001 & $117(15)$ & $129(16)$ & 0.013 \\
\hline $\mathrm{DBP}(\mathrm{mmHg})$ & 582 & $74(10)$ & $77(10)$ & 0.026 & $74(10)$ & $78(12)$ & 0.044 & $69(8)$ & $75(9)$ & 0.002 & $73(10)$ & $79(12)$ & 0.03 \\
\hline $\mathrm{HbA} 1 \mathrm{c}(\mathrm{mmol} / \mathrm{mol})$ & 575 & $45.1(15.4)$ & $56.8(21.2)$ & $<0.001$ & $42.1(8.6)$ & $59.3(23.2)$ & $<0.001$ & $45.6(18.7)$ & $59.9(24.8)$ & 0.003 & $42.5(11.7)$ & $66.5(28.4)$ & $<0.001$ \\
\hline Total Cholesterol (mmol/L) & 571 & $4.9(1.2)$ & $4.5(1.0)$ & 0.002 & $5.0(1.0)$ & $4.5(1.0)$ & 0.003 & $5.0(0.9)$ & $5.2(1.2)$ & 0.357 & $5.1(0.9)$ & $4.7(1.0)$ & 0.162 \\
\hline
\end{tabular}

This article is protected by copyright. All rights reserved. 


\begin{tabular}{|c|c|c|c|c|c|c|c|c|c|c|c|c|c|}
\hline HDL-Cholesterol (mmol/L) & 556 & $1.14(0.37)$ & $1.08(0.31)$ & 0.14 & $1.10(0.31)$ & $1.00(0.30)$ & 0.047 & $1.16(0.35)$ & $1.02(0.23)$ & 0.076 & $1.07(0.34)$ & $0.86(0.17)$ & 0.025 \\
\hline Total Cholesterol/HDL ratio & 557 & $4.7(1.6)$ & $4.5(1.3)$ & 0.24 & $4.8(1.4)$ & $4.8(1.7)$ & 0.99 & $4.6(1.4)$ & $5.3(1.3)$ & 0.037 & $5.2(1.6)$ & $5.6(1.2)$ & 0.29 \\
\hline Total Protein $(\mathrm{g} / \mathrm{L})$ & 585 & $78(11)$ & $81(11)$ & 0.068 & $76(17)$ & $78(12)$ & 0.43 & $73(4)$ & $73(6)$ & 0.99 & $73(16)$ & $72(19)$ & 0.82 \\
\hline Alkaline phosphate (U/L) & 579 & $105(32)$ & $131(42)$ & $<0.001$ & $98(29)$ & $114(35)$ & 0.003 & $77(20)$ & $91(18)$ & 0.001 & $81(23)$ & $89(24)$ & 0.27 \\
\hline Alanine Transferase $(\mathrm{U} / \mathrm{L})$ & 583 & $26(14)$ & $28(18)$ & 0.30 & $35(20)$ & $34(26)$ & 0.90 & $27(14)$ & $29(18)$ & 0.56 & $36(19)$ & $30(14)$ & 0.26 \\
\hline \multicolumn{14}{|c|}{ Median (interquartile range) } \\
\hline Cigarettes (per day*) & 580 & $10(6.5,20)$ & $12(5.5,20)$ & 0.84 & $15(6,25)$ & $13.5(5.5,25)$ & 0.62 & $10(4,17)$ & $8(6,25)$ & 0.37 & $8(5,15)$ & $4(3,25)$ & 0.60 \\
\hline Smoking duration (years)* & 559 & $19(10,28)$ & $22(15,33)$ & 0.05 & $17.5(11,25)$ & $26(18,35)$ & 0.006 & $16(10,21)$ & $12(8,29.6)$ & 0.56 & $14(6,28)$ & $34(25,48.5)$ & 0.09 \\
\hline Creatinine $(\mu \mathrm{mol} / \mathrm{L})$ & 584 & $58(53,68)$ & $70(56,125)$ & $<0.001$ & $81(71,90)$ & $95.5(74,159)$ & $<0.001$ & $60(54,64)$ & $64.5(57,98)$ & 0.021 & $88(79,93)$ & $108(78,140)$ & 0.052 \\
\hline eGFR $\left(\mathrm{ml} / \mathrm{min} / 1.73 \mathrm{~m}^{2}\right)$ & 584 & $105(93,116)$ & $90(39,108)$ & $<0.001$ & $106(93,115)$ & $84(38,105)$ & $<0.001$ & $105(96,116)$ & $95(57,112)$ & 0.01 & $98(84,110)$ & $69.5(49,101)$ & 0.003 \\
\hline v glutamyl transferase (U/L) & 585 & $32(25,52)$ & $41(28,75)$ & 0.007 & $47(28,77)$ & $57(30,89)$ & 0.09 & $21(16,28)$ & $25(19,34)$ & 0.10 & $29(22,40)$ & $25(19,35)$ & 0.22 \\
\hline \multicolumn{14}{|c|}{ Geometric Mean (95\% Confidence interval) } \\
\hline Triglycerides (mmol/L) & 571 & $\begin{array}{c}1.77 \\
(1.63,1.92)\end{array}$ & $\begin{array}{c}2.06 \\
(1.88,2.25)\end{array}$ & 0.015 & $\begin{array}{c}1.79 \\
(1.59,2.02)\end{array}$ & $\begin{array}{c}2.41 \\
(2.11,2.76)\end{array}$ & 0.003 & $\begin{array}{c}1.36 \\
(1.18,1.56)\end{array}$ & $\begin{array}{c}1.73 \\
(1.45,2.07)\end{array}$ & 0.054 & $\begin{array}{c}1.56 \\
(1.32,1.85)\end{array}$ & $\begin{array}{c}2.16 \\
(1.73,2.70)\end{array}$ & 0.057 \\
\hline Bilirubin $(\mu \mathrm{mol} / \mathrm{L})$ & 579 & $5.4(5.0,5.8)$ & $4.8(4.4,5.2)$ & 0.038 & $7.2(6.6,7.9)$ & $5.9(5.2,6.7)$ & 0.14 & $8.9(8.2,9.7)$ & $7.7(6.7,8.9)$ & 0.084 & $10.7(9.7,11.9)$ & $9.8(8.5,11.4)$ & 0.41 \\
\hline
\end{tabular}

* For current smokers 
Table 4: Multivariable linear regression model of log2-albuminuria in all participants

\section{B Coefficient}

Aboriginal ethnicity

Age (years)

Female

Diabetes

Systolic BP $(\mathrm{mmHg})$

eGFR $\left(\mathrm{ml} / \mathrm{min} / 1.73 \mathrm{~m}^{2}\right)$

WHR

Alkaline phosphatase (U/L)

Constant
Microscopic-haem

Use of ACEI /ARB

0.53
-0.02
0.20
1.30
1.52
1.24
0.03
-0.04
2.75
0.01
-2.99

$-0.02$

0.20

1.30

1.52

1.24

0.03

0.01

$-2.99$
95\% Confidence Interval

0.09

$-0.04$

$-0.23$

0.81

1.06

0.77

0.02

$-0.05$

0.25

0.003

$-5.80$

Model $R^{2} 0.56 ; n=517$

Variables in the initial model were selected if they were linearly associated with log2-albuminuria (adjusted for age and gender) in all participants with a $p$ value $<0.10$ as follows: microscopic-haem, diabetes, hypertension, ACEI/ARB use, statin use, aspirin use, systolic blood pressure (BP), diastolic BP, eGFR, HbA1c, triglycerides, total cholesterol, HDL-cholesterol, waist, WHR, serum total bilirubin, alkaline phosphatase (ALP), gamma glutamyl transferase, total protein. Age, gender and indigenous ethnicity (Aboriginal $=1, T S I=0$ ) were forced in the model. Categorical variables were coded $1=$ present, $0=$ absent; continuous variables were included in equation in 1 unit increments.

Log2-albuminuria was converted to ACR (in $\mathrm{mg} / \mathrm{mmol}$ ) using ACR=exp ${ }^{\text {(equation }} \times \log _{2}$ ). Thus $\mathrm{ACR}(\mathrm{mg} / \mathrm{mmol}$ ) is represented as follows:

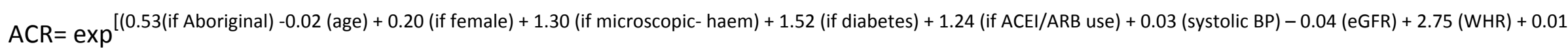
(ALP) -2.99$) \times \log ]$ 
Table 5: Clinical interpretation of effect of each factor on ACR $(\mathrm{mg} / \mathrm{mmol})$ and examples of possible real clinical cases

Additive contribution of each independent variable to estimated ACR expressed as a

percentage increase

Additional percentage to estimated ACR

relative to preceding simulated client

\begin{tabular}{lrrr}
\hline Aboriginal ethnicity & 47 & 9 & 98 \\
Female sex & 15 & -14 & 54 \\
Age (-10 years) & 16 & 4 & 27 \\
Microscopic-haem & 146 & 76 & 243 \\
Diabetes & 186 & 108 & 293 \\
ACEI/ARB & 136 & 70 & 227 \\
Systolic BP (+10 mmHg) & 24 & 16 & 31 \\
eGFR (-10 ml/min/1.73m²) & 26 & 20 & 31 \\
WHR (+ 0.1 units) & 21 & 1 & 43 \\
ALP (+ 10 U/L) & 6 & 2 & 10 \\
\end{tabular}

Estimated ACR $(\mathrm{mg} / \mathrm{mmol})$

\section{Simulations (individual patients)}

\begin{tabular}{rrrrrrrrrrr}
1 & 2 & 3 & 4 & 5 & 6 & 7 & 8 & 9 & 10 & 11 \\
\hline TSI & Aboriginal & Aboriginal & Aboriginal & Aboriginal & Aboriginal & Aboriginal & Aboriginal & Aboriginal & Aboriginal & Aboriginal \\
Male & Male & Female & Female & Female & Female & Female & Female & Female & Female & Female \\
45 & 45 & 45 & 55 & 55 & 55 & 55 & 55 & 55 & 55 & 55 \\
Absent & Absent & Absent & Absent & Present & Present & Present & Present & Present & Present & Present \\
Absent & Absent & Absent & Absent & Absent & Present & Present & Present & Present & Present & Present \\
Absent & Absent & Absent & Absent & Absent & Absent & Present & Present & Present & Present & Present \\
125 & 125 & 125 & 125 & 125 & 125 & 125 & 135 & 135 & 135 & 135 \\
90 & 90 & 90 & 90 & 90 & 90 & 90 & 90 & 80 & 80 & 80 \\
0.90 & 0.90 & 0.90 & 0.90 & 0.90 & 0.90 & 0.90 & 0.90 & 0.90 & 1.00 & 1.00 \\
115 & 115 & 115 & 115 & 115 & 115 & 115 & 115 & 115 & 115 & 125 \\
& & & & & & & & $\mathbf{3 0}$ & \\
\hline 1.3 & $\mathbf{1 . 9}$ & $\mathbf{2 . 1 8}$ & $\mathbf{1 . 8 7}$ & $\mathbf{4 . 5 8}$ & $\mathbf{1 3 . 1 2}$ & $\mathbf{3 0 . 9 6}$ & $\mathbf{3 9 . 0 9}$ & $\mathbf{5 0 . 6 4}$ & $\mathbf{6 1 . 0 3}$ & $\mathbf{6 4 . 8 7}$
\end{tabular}

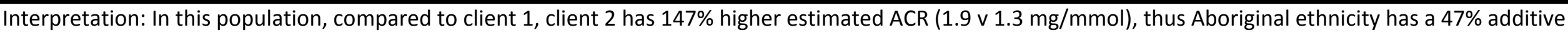

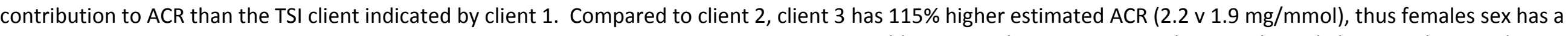
$15 \%$ additive contribution to ACR in clients without diabetes in this population.

This article is protected by copyright. All rights reserved. 


\section{University Library}

\section{- M M N E R VA A gateway to Melbourne's research publications}

Minerva Access is the Institutional Repository of The University of Melbourne

\section{Author/s:}

Hughes, JT;Maple-Brown, LJ;Thomas, M;Lawton, PD;Sinha, A;Cass, A;Barzi, F;Jones, GRD;Jerums, G;Maclsaac, RJ;O'Dea, K;Hoy, WE

Title:

Cross-sectional associations of albuminuria among Aboriginal and Torres Strait Islander adults: the eGFR Study

Date:

2018-01-01

Citation:

Hughes, J. T., Maple-Brown, L. J., Thomas, M., Lawton, P. D., Sinha, A., Cass, A., Barzi, F., Jones, G. R. D., Jerums, G., Maclsaac, R. J., O'Dea, K. \& Hoy, W. E. (2018). Cross-sectional associations of albuminuria among Aboriginal and Torres Strait Islander adults: the eGFR Study. NEPHROLOGY, 23 (1), pp.37-45. https://doi.org/10.1111/nep.12956.

Persistent Link:

http://hdl.handle.net/11343/294042 